\title{
Digitizing Discretionary Practices in Public Service Provision: An Empirical Study of Public Service Workers' Attitudes
}

\author{
Peter André Busch \\ University of Agder, Norway \\ peter.a.busch@uia.no
}

\author{
Tom Eikebrokk \\ University of Agder, Norway \\ tom.eikebrokk@uia.no
}

\begin{abstract}
Public service workers have traditionally enjoyed a wide freedom to make decisions about clients. With the increased use of ICT in public service provision, discretionary practices are influenced or replaced by computerized routines, known as digital discretion. Based on the assumption that public service workers are motivated by helping individual clients, this paper focuses on characteristics of public service provision that can explain their digital discretion acceptance. To find out, we surveyed public service workers $(n=125)$ within several types of public service provision and used structural equation modeling (PLS-SEM). We conclude that professional motivations and the nature of public service provision make it difficult to completely digitize discretionary practices. Policy implications include paying special attention to the opportunities that technological innovations can create and the potential inability of public service workers to fully utilize digital tools due limited training and age.
\end{abstract}

\section{Introduction}

Public service workers have traditionally exercised discretion during policy implementation making decisions about clients within various public services such as policing, social work, and nursing $[25,31]$. Discretion is the professional judgment of public service workers, acquired through years of formal training and experience, which they use to adjust decisions concerning clients and to decide on actions to take (if any) to ensure the best potential outcome [27, 31]. The fundamental dilemma of discretion is that policy outcomes can become different than intended by the policy maker [10, 31]. Public service workers ultimately become policy makers on the street-level ('street-level ministers') where their actions create precedence for similar cases [31]. Digital discretion, the use of information and communications technology (ICT) to influence or replace the professional judgment of public service workers [11], has been introduced to address these policy discrepancies. As a result, face-to-face client interactions on the street-level are replaced with computerized interactions from massive office buildings [5, 43], and public service provision risk becoming less attentive to individual needs of clients. Despite an increasing digitization of public services, little is known about the conditions under which digital discretion becomes prevalent in public service provision [8, 11, 33]. The potential resistance of public service workers is important to understand the success of digitized discretionary services [8]. Moreover, since the purpose of digitized public services is to improve them, the views of public service workers can help us understand if and how public service provision can be improved by digital discretion. Our study is guided by the following research question: which characteristics of public service provision can explain attitudes toward digital discretion among public service workers?

There are different definitions on what constitutes a public service worker. We use the term street-level bureaucrat (SLB) which describes public service workers such as police officers, teachers, nurses, and other professional workers who interact directly with clients and are able to exercise a substantial amount of discretion in their work [31]. A vast majority of studies takes a SLB perspective and explain the necessity of professional judgment by factors such as social complexity [29], job motivation [e.g., 3, 40], a preference for helping clients [e.g., 40], and potential consequences of the decisions public service workers make [e.g., 9, 12]. Other studies identified reduced workload [e.g., 17], increased decision quality [e.g., 7, 12], and mere coercion [e.g., 12, 43] as reasons for why SLBs accept digitized discretionary practices.

Whereas most of the research within this stream has been conducted using qualitative research methods [11, 37], this study is different by drawing upon a quantitative, cross-sectional study. To answer our research question, we first reviewed the literature 
to identify characteristics of public service provision that can explain attitudes toward digital discretion. Characteristics were then operationalized into a survey instrument. 125 SLBs were surveyed representing eight types of public services.

This paper addresses a gap in the knowledge about digital discretion [8, 11]. Our paper has two main contributions. First, we address a gap in the literature that hitherto mostly has studied if discretion is influenced by technology. Results are inconclusive and contextual explanations have largely been ignored. We increase the understanding of how SLBs consider opportunities to digitize discretionary practices and demonstrate the relative importance of public service characteristics to explain attitudes. Our study shows that SLBs within several types of public services are in general reluctant to digital discretion since the nature of public service provision calls for their professional judgment. Moreover, whereas previous research mainly has looked at barriers to digital discretion [11], this study is among the first that, from a SLB perspective, identifies opportunities for digitizing discretionary practices. Government agencies may address these findings when developing and implementing e-government services. Second, we provide measurement scales for the benefit of other e-government researchers.

\section{Related work and model development}

Lipsky [31] acknowledges that the term 'streetlevel bureaucracy' embodies a paradox; namely how SLBs can treat clients alike and at the same time pay attention to individualized concerns. The latter part of the term (bureaucracy) is related to juridical aspects of discretion that constrain SLBs. They are rule followers and the exercise of discretionary power is only possible in cases where rules grant SLBs this power. The former part (street-level) is associated with how rules are interpreted thus enhancing the influence of SLBs in policy implementation.

However, the introduction of ICT has changed the scenery of public service provision [8] and several structural changes have taken place [5]. Client interactions become computerized and automated instead of being handled face-to-face [5, 7, 40, 43]. In some occasions, clients can provide services to themselves through digital self-service solutions [23]. Observing these changes, Bovens and Zouridis [5] claimed that SLBs are turned into screen-level and system-level bureaucrats where the former label describes SLBs relying increasingly on computerized information and the latter label indicates SLBs as mere operators of automated services.
Research suggests that SLBs often find themselves constrained by ICT. Where they previously fully controlled decision-making, ICT is now used to prevent corruption [35, 37] and human errors [e.g., 26], reduce costs of expensive discretionary practices [e.g., 36], increase political legitimacy [e.g., 29], hinder deliberate biases and manipulation of information [e.g., 39, 42], and in general make fairer decisions [e.g., 37]. These changes are welcomed from a top-down perspective where discretion is seen as a problem for policy implementation. From a bottom-up perspective, SLBs are mostly reluctant to any influence on their discretionary power arguing that discretion is necessary to adapt policies to local conditions and to provide just and fair outcomes. ICT can also enable SLBs by providing more information about each client being able to exert control over them [28]. Other findings indicate that ICT is suitable to control formal, but not informal aspects of discretionary practices [8, 30], and that SLBs can hide behind computers (such as in the British comic; "the computer says no!" [43]) reducing judgment costs.

Less attention has been paid to characteristics of public service provision that can lead to digital discretion [8, 11]. Research suggests that digitizing and automating traditional street-level bureaucracies such as courts and schools are challenging [5, 8]. Instead, mass transactional public services seem to be more suitable for digital discretion [5, 11]. Increased standardization of public services such as tax reporting lead to reduced autonomy among SLBs [5, $7,18,33,43]$, even handing power over to system designers that can make choices about how vague legal terms should be interpreted by converting them into algorithms and decision trees that can be decisive for policy outcomes [5, 24].

A variety of reasons can explain why SLBs oppose reduced autonomy [18]. They are often highly professionalized with well-established standards for their occupation and specific entry credentials for their professions [25]. Many are unionized [22] and they have strong opinions about their work [18]. These opinions are often rooted in personal motivations to favor and assist clients whenever possible [40] and in the nature of public service provision [31]. SLBs claim that public services are characterized by challenges such as consequences of decisions $[9,12]$, case complexity $[17,36]$, legislation complexity $[1,10]$, and the need for interaction [17]. We reviewed this literature to develop our model and hypothesize about public service characteristics that can explain SLBs' attitudes toward digital discretion. 


\subsection{Decision complexity}

The exercise of discretion is related to prevailing statutory provisions of law [31]. The legislation that SLBs use as the basis for their decisions may contain terms that invite SLBs to determine the meaning of them $[22,27,29]$. The process of interpreting legal terms can be lengthy and complicated, yet necessary. Since "life comes in so many facets" [9, p. 2967], it will be impossible for policy makers to foresee every situation that can occur. Open-ended rules ensure just decision outcomes. Thus, we hypothesized:

Hypothesis 1a: Legislation complexity will positively influence decision complexity.

Whereas the legislation often has open-ended rules, other rules may use fixed terms reflecting public services that groups of clients are entitled to [35]. Decisions about these services are often based on objective criteria such as age (e.g., whether a child is entitled to a place in kindergarten) and income (e.g., if a student is entitled to receive student grants). Busch [10] found that policy makers were more likely to accept digital discretion in cases where clients are entitled to public services, also expressing views in favor of digital self-service solutions where clients can help themselves whenever possible. We argue that SLBs are likely to reflect the opinions of policy makers since they exercise little or no discretion in these cases. Therefore, we hypothesized that:

Hypothesis 1b: Public service entitlement will negatively influence decision complexity.

Clients can be different in terms of maturity, their need for support, economic status, and life experiences. The situations they represent can vary from simple matters such as over-speeding to serious cases such as murder. The severity of a decision outcome is found to be related to the perceived importance of discretion $[9,12]$. For example, judges can sentence clients to several years in prison and make decisions about child custody matters which obviously create strong emotions among clients involved [9]. The potential decision severity usually means that clients have an ardent desire for SLBs to make professional assessments of their cases. We therefore hypothesized:

Hypothesis 1c: Decision severity will positively influence decision complexity.

\subsection{Public service characteristics, discretion importance, and decision quality}

The complexity of decision-making influences the need clients have to interact with SLBs [37]. Clients often prefer to talk to SLBs arguing that their case is unique and requires a certain outcome [17]. Clients tend to be increasingly satisfied with decisions if they have had the opportunity to present their case and explain their actions directly to a SLB even if the SLB decides on a decision in their disfavor [9]. We hypothesized that:

Hypothesis 2a: Decision complexity will positively influence need for interaction.

Public service provision is characterized by SLBs making decisions about clients. These clients represent circumstances that can be unique and require the attention of SLBs [7, 22, 29]. For example, a criminal may have experienced a traumatic upbringing through which the actions of this client must be understood. Therefore, each case needs to be sufficiently illuminated, and cases that are seemingly similar may be different to some extent which makes it difficult to standardize decision outcomes. This is the reason why SLBs have discretionary power; they must have the opportunity to think creatively and devise appropriate actions adapted to each client if necessary [31]. Thus, our hypothesis became:

$$
\begin{aligned}
& \text { Hypothesis 2b: Decision complexity will } \\
& \text { positively influence perceived importance of } \\
& \text { discretion. }
\end{aligned}
$$

Professional identity is another characteristic that influences the perceived importance of discretion. It refers to whether a SLB identifies herself with the conduct, aims, or qualities that a profession is characterized by. The literature supports the notion that increased identification with a profession favors professional judgment [e.g., 18]. SLBs enjoying a high degree of autonomy (e.g., [1]) and having well established standards for their occupation (e.g., [25]) are more likely to resist digital discretion. A strong professional identity suggests that the decisions SLBs make cannot be made by untrained people [32]. SLBs argue that their unique expertise is necessary to guarantee reasonable decision outcomes. We therefore hypothesized:

Hypothesis 3: Professional identity will positively influence perceived importance of discretion. 
Governments rely increasingly on the use of ICT for implementing policies [33]. Technologies often play a key role for the tasks of SLBs since they devise actions to be taken and provide SLBs with much information [28, 33, 39, 43]. The literature has identified the flexibility of a technological tool to be of importance for how much discretion SLBs can exercise [30]. In some cases, technology is found to reduce the room for maneuver that SLBs have [8]. Technology creates decision paths that need to be followed based on previous choices, and the more choices SLBs make, the more limited will subsequent choices be. Technology can also enhance the room for maneuver. By being flexible, supporting existing work practices, and providing more information, the perceived importance of discretion increases. We therefore hypothesized:

\section{Hypothesis 4: Technology flexibility will positively influence perceived importance of} discretion.

Information quality is identified as being important to the quality of decisions. With ICT, SLBs now have access to vast amounts of information that can help them make better decisions [9, 24]. Information quality is often related to the term 'fit for use' which denotes how information need characteristics that allows it to be applied and used in a specific context and in an understandable format for its users. Information may be erroneous for several reasons. For example, public agencies storing and handling client data multiple times, wrong data inputs from external organizations such as financial institutions, and clients deliberately providing incorrect information $[16,24]$. We hypothesized that:

Hypothesis 5: Information quality will positively influence perceived decision quality.

\subsection{Attitude toward digital discretion}

Computer self-efficacy refers to an individual's perception of its own ability to use technology to accomplish as task $[6,15]$. The term implies that a computer is used to accomplish specific tasks. Since Compeau \& Higgins [15] first developed their measure of computer self-efficacy in 1995, ICT has changed considerably. In the mid-90's, ICT was purchased and installed at workplaces. Today, ICT refers to a variety of technologies such as smart phones, smart watches, tablets, cloud applications etc. Therefore, when we refer to the use of technology, we mean use in a broad sense including a variety of technologies. Although computer self- efficacy is not specific to the use of discretion, empirical evidence suggests that SLBs with greater computer self-efficacy will perceive discretion in decision-making processes to be less relevant $[9,12]$. Like Compeau \& Higgins [14] demonstrated that task performance increases with increased computer selfefficacy, we argue that SLBs mastering technology also rely more on the choices and decisions it makes [37]. Thus, we hypothesized:

Hypothesis 6: Computer self-efficacy will positively influence attitude toward digital discretion.

Research shows that digital discretion is difficult to utilize in traditional public service work such as in courts and schools [5, 8]. Mass transactional public services such as loan assessments and police controlling over-speeding seem to be more suitable for digital discretion $[5,11]$. SLBs argue that public policies need to be interpreted and adapted to real-life situations [8, 11, 17, 29, 31]. By doing so, the quality of their decisions increases since they can produce outcomes that are more fair and reasonable taking individual circumstances into consideration [7]. Moreover, the more important SLBs consider discretion to be for their work, the less positive they are toward digital discretion [11]. We therefore hypothesized:

Hypothesis 7: Perceived importance of discretion will positively influence perceived decision quality.

Hypothesis 8a: Perceived importance of discretion will negatively influence attitude toward digital discretion.

The literature supports the notion that perceived decision quality is important to explain whether SLBs accept digital discretion or not. Whereas SLBs in general are reluctant to digital discretion, they are more likely to accept it in cases where they can see that public services are improved. Research suggests that SLBs will prioritize professional norms over managerial goals if they are required to do so [40]. A positive attitude reflects beliefs that computers, under certain circumstances, can make decisions that are better than the decisions they make themselves [5, 42]. Whether a decision is better or not is judged in terms of whether SLBs believe that computerized decisions follow the norms of their profession [40]. Our hypothesis was therefore:

Hypothesis 8b: Perceived decision quality will positively influence attitude toward digital discretion. 
Figure 1 presents our research model and hypotheses.

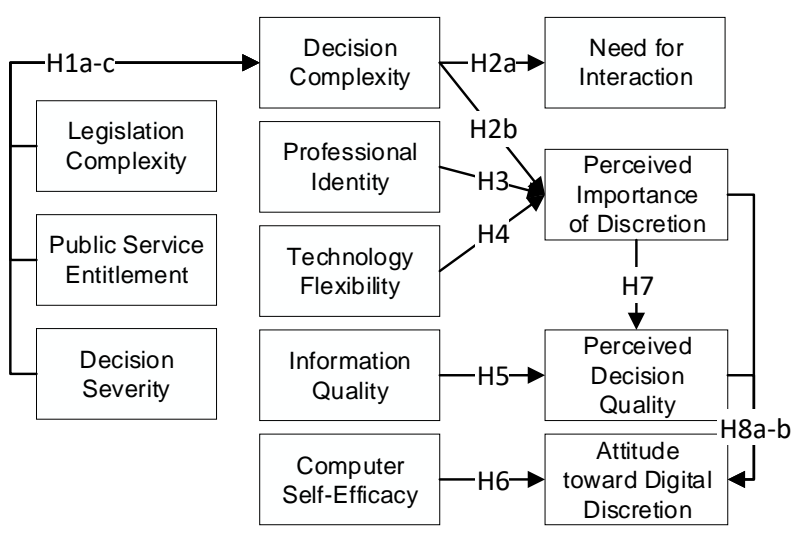

Figure 1. Research model

\section{Survey methodology}

To test our hypotheses, we conducted a crosssectional study of 125 SLBs within several types of public service provision.

\subsection{Data collection and sample statistics}

We used the definition of street-level bureaucracies by Lipsky [31] when selecting public agencies. A random sample of public agencies in Norway was drawn from agencies providing several types of public services. Potential agencies were contacted through phone and e-mail. Executives were informed about the research project and subsequently invited to participate. Executives then distributed the survey link to respondents. We offered gift certificates to increase participation (they were given to two of the respondents after a draw). In total, 125 SLBs completed the survey whereof $90(72 \%)$ used the gift certificate option. Respondents from several types of public service provision participated: food safety authority (FSA), public roads administration (PRA), directorate of fisheries (DF), customs offices (CO), county governor office (CGO), courts (CRT), municipal building planning and permit offices (BPO), and municipal kindergarten administration offices (KAO). Whereas some of the SLBs conduct field inspections (FSA, PRA, DF, CO), often alone, other SLBs work with case handling (CGO, CRT, $\mathrm{BPO}, \mathrm{KAO})$.

No missing values were reported. The mean work experience was 19.6 years $(\mathrm{SD}=11.4)$ ranging from 0 to 45 years. The respondents used two types of technologies. Those working with field inspections mainly use handheld devices with apps installed. SLBs working with case handling use case management systems. Table 1 provides an overview of the final sample with its respondents and streetlevel bureaucracies.

\section{Table 1. Sample statistics}

\begin{tabular}{|l|l|l|l|}
\hline $\begin{array}{l}\text { Years work } \\
\text { experience }\end{array}$ & $\begin{array}{l}\text { \# of } \\
\text { respondents }\end{array}$ & $\begin{array}{l}\text { Type of } \\
\text { public service }\end{array}$ & $\begin{array}{l}\text { \# of } \\
\text { respondents }\end{array}$ \\
\hline $0-5$ & 17 & FSA & 17 \\
\hline $6-10$ & 18 & PRA & 21 \\
\hline $11-15$ & 12 & DF & 26 \\
\hline $16-20$ & 20 & CGO & 8 \\
\hline $21-25$ & 25 & CO & 4 \\
\hline $26-30$ & 11 & CRT & 21 \\
\hline $31-35$ & 6 & BPO & 19 \\
\hline $36-$ & 16 & KAO & 9 \\
\hline
\end{tabular}

\subsection{Operationalization of constructs}

The operationalization of constructs combined previously validated indicators with new indicators developed to fit the context. Computer self-efficacy (CSE) was operationalized with four items adapted from Sasidharan et al. [38]. Information quality (IQ) used four adapted indicators from $\mathrm{Au}$ et al. [2]. Decision complexity (DC) was measured with five indicators from Barki et al. [4]. Perceived decision quality (PDQ) was measured with items adapted from Paul et al. [34]. Attitude toward digital discretion (ADD) was adapted from Venkatesh et al. [41].

We developed several items based on extant literature and 16 interviews with SLBs in context conducted prior to the survey. Candidate indicators was pretested on three IS researchers and four SLBs. A list of questions was presented to subjects who assessed them according to the constructs. Based on the results of the pretest, questions were rephrased or deleted from the candidate list. Items were developed for the following constructs: decision severity (DS), technology flexibility (TF), professional identity (PI), need for interaction (NI), legislation complexity (LC), perceived importance of discretion (PID), and public service entitlement (PSE). In addition to the multi-item measures, questions about type of work and work experience (in years) were collected.

The original measurement instrument had four and five items for each construct. To avoid survey fatigue, all constructs were adapted to and measured by using 7-points semantic-differentials scales [13]. During our analysis, several indicators were dropped due insufficient loadings. The measurement instrument with retained indicators is shown in the Appendix (the complete measurement instrument is 
available upon request). For the convenience of the respondents, the questionnaire was presented to them in Norwegian.

\section{Data analysis and results}

Data analysis and hypotheses testing were conducted using structural equation modeling with the partial least squares (PLS) estimation technique using SmartPLS. We adopted best practices for reporting PLS-SEM results from Hair et al. [19].

\subsection{Instrument validation}

The first part of our analyses included instrument validation through four steps starting with indicator reliability. Initially, our constructs had four or five indicators and our analysis revealed to low indicator loadings for some constructs. The model was subsequently modified by removing indicators that had unsatisfactory loadings. After the modification, we found that all outer loadings (OL) were above the recommended level of .70 except for CSE3 (.689) which is acceptable in exploratory research [21].

Second, the internal consistency reliability of the constructs was evaluated by their composite reliability (CR). All CR values were above the recommended value .70 [19]. Cronbach's Alpha was omitted since it assumes that all indicators of a construct are equally reliable [20].

Third, we assessed convergent validity by using the constructs' average variance extracted (AVE). All AVE values were above the recommended threshold of .50 [19]. These tests showed satisfactory values, and the variance caused by random errors did not challenge the validity of the model.

Table 2. Measurement reliability and validity

\begin{tabular}{|c|c|c|c|c|c|c|c|c|c|}
\hline Con. & Item & $\mathrm{OL}$ & CR & AVE & Con. & Item & $\mathrm{OL}$ & CR & AVE \\
\hline \multirow[t]{2}{*}{ CSE } & CS3 & 689 & \multirow[t]{2}{*}{.766} & \multirow[t]{2}{*}{.624} & \multirow[t]{2}{*}{$\mathrm{NI}$} & $\mathrm{NI} 2$ & .905 & \multirow[t]{2}{*}{.916} & \multirow[t]{2}{*}{.846} \\
\hline & CS4 & .879 & & & & $\mathrm{NI4}$ & .935 & & \\
\hline \multirow[t]{3}{*}{ DC } & $\mathrm{DC1}$ & .775 & \multirow[t]{3}{*}{.838} & \multirow[t]{3}{*}{.634 } & \multirow[t]{3}{*}{ LC } & LC1 & .763 & \multirow[t]{3}{*}{.824} & \multirow[t]{3}{*}{.609 } \\
\hline & $\mathrm{DC} 2$ & 877 & & & & LC2 & .806 & & \\
\hline & DC4 & .730 & & & & LC3 & .772 & & \\
\hline \multirow[t]{3}{*}{ DS } & DS1 & .859 & \multirow[t]{3}{*}{.877} & \multirow[t]{3}{*}{.703} & \multirow[t]{2}{*}{ PID } & ID1 & .880 & \multirow[t]{2}{*}{.855} & \multirow[t]{2}{*}{.747} \\
\hline & DS3 & .827 & & & & ID3 & .848 & & \\
\hline & DS4 & .830 & & & \multirow[t]{2}{*}{ PSE } & PS2 & .811 & \multirow[t]{2}{*}{.854} & \multirow[t]{2}{*}{.745} \\
\hline \multirow[t]{2}{*}{ TF } & TF2 & .936 & \multirow[t]{2}{*}{833} & \multirow[t]{2}{*}{ 716 } & & PS4 & .912 & & \\
\hline & TF5 & .746 & & & \multirow[t]{4}{*}{ PDQ } & DQ1 & .835 & \multirow[t]{4}{*}{.879} & \multirow[t]{4}{*}{.645} \\
\hline \multirow[t]{4}{*}{$\mathrm{PI}$} & $\mathrm{PI} 1$ & .746 & \multirow[t]{4}{*}{.848} & \multirow[t]{4}{*}{.584} & & DQ2 & .846 & & \\
\hline & $\mathrm{PI} 2$ & .784 & & & & DQ3 & .746 & & \\
\hline & $\mathrm{PI} 4$ & .810 & & & & DQ4 & .781 & & \\
\hline & PI5 & .712 & & & \multirow[t]{4}{*}{ ADD } & AD1 & .869 & \multirow[t]{4}{*}{929} & \multirow[t]{4}{*}{.767} \\
\hline IQ & IQ1 & .769 & 869 & .688 & & AD2 & 853 & & \\
\hline & IQ2 & .879 & & & & AD4 & .908 & & \\
\hline & IQ3 & .837 & & & & AD5 & .872 & & \\
\hline
\end{tabular}

The fourth step assessed the discriminant validity (DV) of the constructs through the Fornell-Larcker criterion [21] and revealed that all indicators loaded higher on their respective constructs. The square root of each construct's AVE was higher than correlations between constructs. Reliability and validity metrics are summarized in Table 2.

\subsection{Model validation}

Figure 2 shows the research model with path coefficients $(\beta)$, hypotheses, and explained variance of endogenous variables $\left(\mathrm{R}^{2}\right)$.

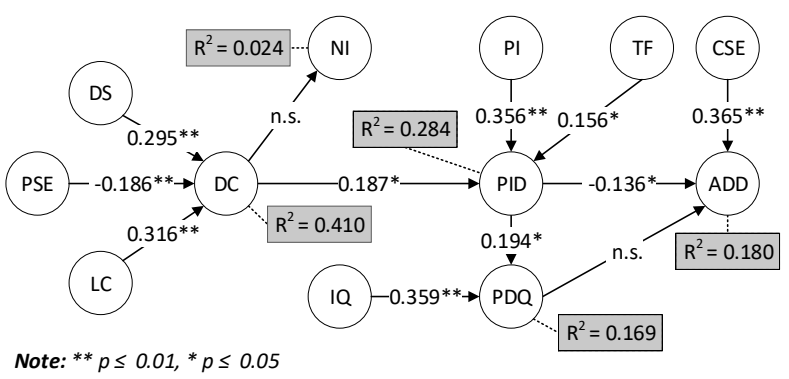

Figure 2. Results of hypotheses tests

As depicted in Figure 2, ten of our 12 hypotheses were empirically supported. Decision severity $(\beta=$ $.295, \mathrm{t}=3.003, \mathrm{p}<.01)$ and legislation complexity $(\beta=$ $.316, \mathrm{t}=3.643, \mathrm{p}<.01)$ are found to have positive and significant impacts on decision complexity. A significant negative influence of public service entitlement on decision complexity was found $(\beta=-$ $.186, \mathrm{t}=2.340, \mathrm{p}<.01)$. The model predicted $41.0 \%$ of the variance for decision complexity $\left(\mathrm{R}^{2}=.410\right)$.

Additionally, decision complexity is found to exert a positive and significant influence on the perceived importance of discretion in public service provision $(\beta=.187, \mathrm{t}=1.992, \mathrm{p}<.05)$. Professional identity is positively linked with perceived importance of discretion $(\beta=.356, \mathrm{t}=3.947, \mathrm{p}<.01)$ as well as technology flexibility $(\beta=.156, t=1.661$, $\mathrm{p}<.05)$. Moreover, both information quality $(\beta=.359$, $\mathrm{t}=4.566, \quad \mathrm{p}<.01)$ and perceived importance of discretion $(\beta=.194, \mathrm{t}=2.098, \mathrm{p}<.05)$ exert positive and significant influences on how SLBs perceive decision quality. Our structural model predicts $28.4 \%$ of the variance for perceived importance of discretion $\left(\mathrm{R}^{2}=.284\right)$ and $16.9 \%$ for perceived decision quality $\left(\mathrm{R}^{2}=.169\right)$.

Perceived importance of discretion $(\beta=-.136, \mathrm{t}=$ $1.737, \mathrm{p}<.05)$ and computer self-efficacy $(\beta=.365, \mathrm{t}$ $=4.521, \mathrm{p}<.01$ ) explained SLBs attitudes toward digital discretion with an explained variance $\mathrm{R}^{2}$ of 
.180. This coefficient of determination represents weak predictive power [21]. Table 3 sums up results from the hypotheses testing.

\section{Table 3. Summary of hypotheses tests}

\begin{tabular}{|l|l|l|l|}
\hline Hypotheses & $\begin{array}{l}\text { Independent } \\
\text { variables }\end{array}$ & $\begin{array}{l}\text { Dependent } \\
\text { variables }\end{array}$ & Support \\
\hline H1a & LC & DC & Yes \\
\hline H1b & PSE & DC & Yes \\
\hline H1c & DS & DC & Yes \\
\hline H2a & DC & NI & n.s. \\
\hline H2b & DC & PID & Yes \\
\hline H3 & PI & PID & Yes \\
\hline H4 & TF & PID & Yes \\
\hline H5 & IQ & PDQ & Yes \\
\hline H6 & CSE & ADD & Yes \\
\hline H7 & PID & PDQ & Yes \\
\hline H8a & PID & ADD & Yes \\
\hline H8b & PDQ & ADD & n.s. \\
\hline
\end{tabular}

The model is further evaluated by looking at effect size $\left(\mathrm{f}^{2}\right)$. This measure allows us to assess the contributions of exogenous constructs on endogenous constructs by simulating the inclusion and exclusion of exogenous constructs [21]. All exogenous constructs showed either weak $\left(\mathrm{f}^{2}>=.02\right)$ or moderate $\left(f^{2}>=.15\right)$ effects on their respective endogenous constructs [19] except the non-significant influence of perceived decision quality on attitude toward digital discretion. This effect size was below the acceptable minimum $\left(\mathrm{f}^{2}=.01\right)$.

As our final assessment, we validated the model by the predictive relevance of exogenous constructs $\left(\mathrm{Q}^{2}\right)$ and effect size $\left(\mathrm{q}^{2}\right)$, as shown in Table 4.

\section{Table 4. Predictive relevance and effect size}

\begin{tabular}{|c|c|c|c|c|c|}
\hline Relations & $q^{2}$ & Q2 & Relations & $q^{2}$ & Q2 \\
\hline $\mathrm{LC} \cdot \mathrm{DC}$ & .05 & \multirow[t]{3}{*}{.23} & IQ·PDQ & .08 & \multirow[t]{2}{*}{.10} \\
\hline PSE•DC & .01 & & PID•PDQ & .02 & \\
\hline DS·DC & .05 & & PID-ADD & .01 & \multirow[t]{4}{*}{.12} \\
\hline DC·PID & .02 & \multirow[t]{3}{*}{.18} & PDQ $\cdot A D D$ & .00 & \\
\hline PI•PID & .08 & & CSE-ADD & .10 & \\
\hline TF•PID & .01 & & & & \\
\hline
\end{tabular}

We performed a blindfolding procedure (omission distance=7) suggesting that decision complexity $\left(\mathrm{Q}^{2}=.231\right)$, need for interaction $\left(\mathrm{Q}^{2}=.011\right)$, perceived importance of discretion $\left(\mathrm{Q}^{2}=.180\right)$, perceived decision quality $\left(\mathrm{Q}^{2}=.095\right)$, and attitude toward digital discretion $\left(\mathrm{Q}^{2}=.117\right)$ have sufficient predictive relevance $[19,21]$. The effect size $\mathrm{q}^{2}$ was calculated manually for each construct and revealed either weak $\left(\mathrm{q}^{2}>=.02\right.$ and $\mathrm{q}^{2}<.15$ [19]) or unsatisfactory effect size of predictive relevance $\left(\mathrm{q}^{2}<.02[19]\right)$.

\section{Discussion}

The goal of this research was to understand how SLBs consider opportunities to digitize discretionary practices. Whereas Lipsky [31] argued that "the nature of service provision calls for human judgment that cannot be programmed and for which machines cannot substitute" (p. 161), the literature has shown that public services are increasingly digitized [5, 43] and that novel technologies create opportunities for innovation in the way public services are provided $[8$, $10,11]$. This research is exploratory, and we have tested a potential conceptualization of digital discretion acceptance encouraging further theorization. In our theoretical model, we tested 12 hypotheses relating characteristics of public service provision with SLBs' attitudes toward digital discretion. We found empirical support for our model using empirical data from 125 SLBs preoccupied with several types of public services.

This study makes two important contributions. First, we contribute by addressing a gap in the literature and empirically testing theoretical assumptions [8, 11]. The relationships between public service characteristics and SLBs' attitudes toward digital discretion have received little attention in previous research. Our study reveals the influence of factors that can explain how discretion, decision quality, and digital discretion are perceived among SLBs. Moreover, we also identify opportunities for digitizing discretionary practices from a SLB perspective which is less researched in extant literature. Second, we provide measurement scales that, although in an early stage of validation, can be useful for further research within e-government.

\subsection{Implications and future research}

This study has looked at SLBs' resistance and accept for digitized discretionary practices. We identified two main explanations for their attitudes toward digital discretion. First, how and why SLBs consider discretion as important can contribute to our understanding of attitudes toward digital discretion. Our study identified professional identity as the strongest explanation for the perceived importance of discretion followed by decision complexity. Considering that SLBs often are highly professionalized, these findings imply that if public services, and discretionary practices in particular, are to be digitized, government agencies need to address 
how professional norms can be achieved. SLBs are strongly motivated by helping clients, and their support of digitized services depends on the professional outcome the digitization. Decision complexity is closest to describe the nature of public service provision which Lipsky [31] identified as the main problem with digitizing public services. There is something about the complexity of life that makes discretion inevitable, and digital discretion research seem to confirm that it is difficult to remove or influence discretionary practices within traditional street-level bureaucracies $[5,11]$.

Second, computer self-efficacy is strongly linked to a positive attitude toward digitizing discretionary practices. Reasons for this can be that people with high computer self-efficacy are more likely to understand the opportunities and challenges that digital discretion represents. Since they can see the benefit of it, they are also more likely to accept an influence [9, 12]. Similarly, information quality is positively associated with a perception of better decisions.

Two hypotheses were non-significant. Related to $\mathrm{H} 2 \mathrm{a}$, it is possible that the indirect measurement of the clients' need for interaction is not able to sufficiently capture precise information regarding the clients' situations. Future studies should explore other and more direct operationalizations of the clients' need for interaction. A missing finding regarding $\mathrm{H} 8 \mathrm{~b}$ may be due to external factors that affect decision quality (e.g., time and other resources). Since these are factors not related to digitization, they are not relevant for measuring the attitude towards digital discretion.

These findings serve as starting points for future research on barriers and enablers to the digitization of discretionary practices. Two aspects of particular interest are the potential connection between specific e-government features and SLBs' attitudes toward digital discretion, and second, how SLBs conducting different types of tasks respond to increased digitization. This would entail a comparison between innovations in public service provision such as artificial intelligence and traditional technologies to find out if decision complexity and individualized concerns can be addressed. Moreover, the tasks of SLBs within different occupations should be examined to find out how different tasks relate to different digital tools and SLBs' attitudes toward digital discretion. Whereas this study has focused specifically on SLBs' attitudes, other factors should be investigated to understand opportunities for digitizing discretionary practices. For example, how technology can influence discretionary practices regardless of SLBs' attitudes and political priorities.

\subsection{Limitations}

Despite our contributions, we recognize that our study has some limitations. First, our sample consists of SLBs exclusively residing in Norway with shared understandings of public service provision. Acknowledging this shortcoming, we hold that Norway represents SLBs in a highly industrialized country comparable to other top-ranking egovernment countries in the world. Second, whereas some public services are underrepresented (and others not represented) in our sample, we have tested a possible conceptualization of digital discretion acceptance with respondents representing a wider variety of public service provision than most other studies within this stream. Third, the validation of our model shows low values on some metrics. However, we argue that our study represents early theory development about digital discretion acceptance, and that lower values are common and acceptable in exploratory studies [19]. And fourth, the number of respondents $(n=125)$ is relatively low and future studies should seek to increase sample size.

\section{Appendix: measurement instrument}

Technology Flexibility (TF)

2 . When using technology, decisions are often

... taken by the system (1) - (7) taken by me*

5. In general, I experience that technology has led to

... reduced use of discretion (1) - (7) increased use of discretion*

Information Quality (IQ)

1. I often experience that the software provides information that is ... completely wrong (1) - (7) completely correct

2. I often experience that the software provides information that is ... totally irrelevant (1) - (7) very relevant

3. I often experience that the software provides information that is ... completely outdated (1) - (7) completely updated

Decision Severity (DS)

1. My clients often perceive my decisions as

... completely unimportant (1) - (7) crucial*

3. My decisions affect the lives of my clients

... to a small extent (1) - (7) to a considerable extent*

4. To my clients, my decision outcomes are often

... uninteresting (1) - (7) interesting*

Decision Complexity (DC)

1. When I make decisions, I must often take

... identical factors into account (1) - (7) a range of factors into account

2. When I make decisions, I must often take

... a few factors into account (1) - (7) many factors into account

4. The decisions I make are

... always routine (1) - (7) always new

Need for Interaction (NI)

2. When I make decisions, clients often consider personal interaction with me as

... completely unimportant (1) - (7) crucial*

(continued) 
4. Often, my clients consider the ability to present their case personally to me, as

... completely unimportant (1) - (7) crucial*

Legislation Complexity (LC)

1. Often, the legislation has

... definitive terms (1) - (7) discretionary terms*

2. Usually, an interpretation of the legislation is

... completely unnecessary (1) - (7) completely necessary*

3 . The context, in which a legal rule is applied, is often

... completely insignificant (1) - (7) crucial*

Public Service Entitlement (PSE)

2. Often, I experience the outcomes of my decisions to be

... my judgments (1) - (7) predetermined*

4. When I make decisions, I exercise discretion

... to a less extent (1) - (7) to a large extent (R)*

\section{Computer Self-Efficacy (CSE)}

3. If there is little time to complete my work tasks, to complete them with an unfamiliar technology would be

... difficult (1) - (7) easy

4. If I am shown how to do my work tasks using a technology, to

complete them would be

... difficult (1) - (7) easy

\section{Professional Identity (PI)}

1. The decisions I make

... can be taken by most people (1) - (7) must be taken by professionals*

2. Usually, the decisions I make require

... no formal education (1) - (7) formal education*

4. To make decisions, my professional training is often

... completely unnecessary (1) - (7) completely necessary*

5. Often, I experience that the decisions I make require

... general skills (1) - (7) specialized skills*

Perceived Importance of Discretion (PID)

1. Often, when I make decisions about clients, discretion is

... completely unnecessary (1) - (7) completely necessary*

3. I often experience that my decisions

... can be easily standardized (1) - (7) cannot be standardized*

Perceived Decision Quality (PDQ)

1. I often experience that my decisions are

... unfair (1) - (7) fair

2. I often experience that my decisions have

... bad outcomes (1) - (7) good outcomes

3. Once I have made a decision, I often have

... a bad conscience (1) - (7) a clear conscience

4. Often, I experience that my decisions are based on

... a poor foundation (1) - (7) a solid foundation

Attitude Toward Digital Discretion (ADD)

1. Using technology to influence my decision-making is

... a bad idea (1) - (7) a good idea

2. If a technology can influence my decisions, I will

... not use it (1) - (7) prefer to use it

4. I consider the use of technology in decision-making as

... unfavorable (1) - (7) favorable

5. I consider the use of technology in decision-making as ... damaging (1) - (7) beneficial

* Indicators developed in this research

\section{References}

[1] Aas, K.F., "Sentencing Transparency in the Information Age", Journal of Scandinavian Studies in Criminology and Crime Prevention, 5(1), 2004, pp. 48-61.

[2] Au, N., Ngai, E.W., and Cheng, T.E., "Extending the Understanding of End User Information Systems Satisfaction Formation: An Equitable Needs Fulfillment Model Approach", MIS Quarterly, 32(1), 2008, pp. 43-66.

[3] Bakker, A.B., "A Job Demands-Resources Approach to Public Service Motivation", Public Administration Review, 75(5), 2015, pp. 723-732.

[4] Barki, H., Rivard, S., and Talbot, J., "Toward an Assessment of Software Development Risk", Journal of MIS, 10(2), 1993, pp. 203-225.

[5] Bovens, M., and Zouridis, S., "From Street-Level to System-Level Bureaucracies: How Information and Communication Technology is Transforming Administrative Discretion and Constitutional Control", Public Administration Review, 62(2), 2002, pp. 174-184.

[6] Brown, S.A., Dennis, A.R., and Venkatesh, V., "Predicting Collaboration Technology Use: Integrating Technology Adoption and Collaboration Research", Journal of MIS, 27(2), 2010, pp. 9-54.

[7] Bruhn, A., "Changing Occupational Roles in Audit Society-The Case of Swedish Student Aid Officials", Nordic Journal of Working Life Studies, 5(1), 2015, pp. 3150.

[8] Buffat, A., "Street-Level Bureaucracy and EGovernment", Public Management Review, 17(1), 2015, pp. 149-161.

[9] Busch, P.A., "The Role of Contextual Factors in the Influence of ICT on Street-Level Discretion", in (Bui, T., and Sprague Jr., R.H., 'eds.'): Proceedings of the 50th Hawaii International Conference on System Sciences (HICSS), Big Island, HI, 2017, pp. 2963-2972.

[10] Busch, P.A., "Conceptualizing Digital Discretion Acceptance in Public Service Provision: A Policy Maker Perspective": Proceedings of the 22nd Pacific Asia Conference on Information Systems (PACIS), Yokohama, Japan, 2018

[11] Busch, P.A., and Henriksen, H.Z., "Digital Discretion: A Systematic Literature Review of ICT and Street-Level Discretion", Information Polity, 23(1), 2018, pp. 3-28.

[12] Busch, P.A., Henriksen, H.Z., and Sæbø, Ø., "Opportunities and Challenges of Digitized Discretionary Practices: a Public Service Worker Perspective", Government Information Quarterly, 2018, https://doi.org/10.1016/j.giq.2018.09.003.

[13] Chin, W.W., Johnson, N., and Schwarz, A., "A Fast Form Approach to Measuring Technology Acceptance and Other Constructs", MIS Quarterly, 32(4), 2008, pp. 687703.

[14] Compeau, D.R., and Higgins, C.A., "Application of Social Cognitive Theory to Training for Computer Skills", Information Systems Research, 6(2), 1995, pp. 118-143.

[15] Compeau, D.R., and Higgins, C.A., "Computer SelfEfficacy: Development of a Measure and Initial Test", MIS Quarterly, 19(2), 1995, pp. 189-211.

[16] Dawes, S.S., and Helbig, N., "The Value and Limits of Government Information Resources for Policy 
Informatics", in (Johnston, E.W., 'ed.'): Governance in the Information Era: Theory and Practice of Policy Informatics, Routledge, London, UK, 2015, pp. 25-34.

[17] De Witte, J., Declercq, A., and Hermans, K., "StreetLevel Strategies of Child Welfare Social Workers in Flanders: The Use of Electronic Client Records in Practice", British Journal of Social Work, 46(5), 2016, pp. 1249-1265.

[18] Giest, S., and Raaphorst, N., "Unraveling the Hindering Factors of Digital Public Service Delivery at Street-Level: The Case of Electronic Health Records", Policy Design and Practice, 1(2), 2018, pp. 141-154.

[19] Hair, J., Hollingsworth, C.L., Randolph, A.B., and Chong, A.Y.L., "An Updated and Expanded Assessment of PLS-SEM in Information Systems Research", Industrial Management \& Data Systems, 117(3), 2017, pp. 442-458.

[20] Hair, J.F., Sarstedt, M., Ringle, C.M., and Mena, J.A., "An Assessment of the Use of Partial Least Squares Structural Equation Modeling in Marketing Research", Journal of the Academy of Marketing Science, 40(3), 2012, pp. 414-433.

[21] Hair Jr, J.F., Hult, G.T.M., Ringle, C., and Sarstedt, M., A Primer on Partial Least Squares Structural Equation Modeling (PLS-SEM), SAGE Publications, Thousand Oaks (CA), 2014.

[22] Henman, P., and Adler, M., "Information Technology and the Governance of Social Security", Critical Social Policy, 23(2), 2003, pp. 139-164.

[23] Henriksen, H.Z., "Scrutinizing Open Government Data to Understand Patterns in E-Government Uptake", in (Tambouris, E., Janssen, M., Scholl, H.J., Wimmer, M.A., Tarabanis, K., Gascó, M., Klievink, B., Lindgren, I., and Parycek, P., 'eds.'): Electronic Government. EGOV 2015. Lecture Notes in Computer Science, vol 9248, Springer, Cham, 2015, pp. 144-155.

[24] Henriksen, H.Z., "One Step Forward and Two Steps Back: E-Government Policies in Practice", in (Gil-Garcia, J., Pardo, T., and Luna-Reyes, L., 'eds.'): Policy Analytics, Modelling, and Informatics, Springer, Cham, Germany, 2018, pp. 79-97.

[25] Hill, M., and Hupe, P., Implementing Public Policy : An Introduction to the Study of Operational Governance, SAGE, 3rd edn, London, UK, 2014.

[26] Houston, S., "Reducing Child Protection Error in Social Work: Towards a Holistic-Rational Perspective", Journal of Social Work Practice, 29(4), 2015, pp. 379-393.

[27] Hupe, P., "Dimensions of Discretion: Specifying the Object of Street-Level Bureaucracy Research", Der moderne Staat: Zeitschrift für Public Policy, Recht und Management, 6(2), 2013, pp. 425-440.

[28] Hupe, P., and Buffat, A., "A Public Service Gap: Capturing Contexts in a Comparative Approach of StreetLevel Bureaucracy", Public Management Review, 16(4), 2014, pp. 548-569.

[29] Jansson, G., and Erlingsson, G.Ó., "More EGovernment, Less Street-Level Bureaucracy? On Legitimacy and the Human Side of Public Administration", Journal of Information Technology \& Politics, 11(3), 2014, pp. 291-308.
[30] Jorna, F., and Wagenaar, P., "The 'Iron Cage' Strengthened? Discretion and Digital Discipline", Public Administration, 85(1), 2007, pp. 189-214.

[31] Lipsky, M., Street-Level Bureaucracy: Dilemmas of the Individual in Public Services, Russell Sage Foundation, 30th anniversary expanded edn, New York (NY), 2010.

[32] Marston, G., "Employment Services in an Age of EGovernment", Information, Community and Society, 9(1), 2006, pp. 83-103.

[33] Meijer, A., "Complex Responsibilities: An Empirical Analysis of Responsibilities and Technological Complexity in Dutch Immigration Policies", Public Management Review, 11(6), 2009, pp. 771-790.

[34] Paul, S., Samarah, I.M., Seetharaman, P., and Mykytyn jr., P.P., "An Empirical Investigation of Collaborative Conflict Management Style in Group Support System-Based Global Virtual Teams", Journal of MIS, 21(3), 2004, pp. 185-222.

[35] Paulin, A., "Towards Self-Service Government-A Study on the Computability of Legal Eligibilities", Journal of Universal Computer Science, 19(12), 2013, pp. 17611791.

[36] Pithouse, A., Broadhurst, K., Hall, C.J., Peckover, S., Wastell, D., and White, S., "Trust, Risk and the (Mis)management of Contingency and Discretion through New Information Technologies in Children's Services", Journal of Social Work, 12(2), 2011, pp. 158-178.

[37] Reddick, C., Abdelsalam, H.M., and Elkadi, H., "The Influence of E-Government on Administrative Discretion: the Case of Local Governments in Egypt", Public Administration \& Development, 31(5), 2011, pp. 390-407.

[38] Sasidharan, S., Santhanam, R., Brass, D.J., and Sambamurthy, V., "The Effects of Social Network Structure on Enterprise Systems Success: A Longitudinal Multilevel Analysis", Information Systems Research, 23(3 part-1), 2012, pp. 658-678.

[39] Snellen, I., "Street Level Bureaucrats", in (Snellen, I., Thaens, M., and van de Donk, W., 'eds.'): Public Administration in the Information Age: Revisited, IOS Press, Amsterdam (NY), 2012, pp. 264-278.

[40] Tummers, L., and Rocco, P., "Serving Clients When the Server Crashes: How Frontline Workers Cope with EGovernment Challenges", Public Administration Review, 75(6), 2015, pp. 817-827.

[41] Venkatesh, V., Morris, M.G., Davis, G.B., and Davis, F.D., "User Acceptance of Information Technology: Toward a Unified View", MIS Quarterly, 27(3), 2003, pp. 425-478.

[42] Wenger, J.B., and Wilkins, V.M., "At the Discretion of Rogue Agents: How Automation Improves Women's Outcomes in Unemployment Insurance", Journal of Public Administration Research and Theory, 19(2), 2009, pp. 313333.

[43] Wihlborg, E., Larsson, H., and Hedström, K., "'The Computer Says No!"- a Case Study on Automated Decision-Making in Public Authorities", in (Bui, T., and Sprague Jr., R.H., 'eds.'): Proceedings of the 49th Hawaii International Conference on System Sciences (HICSS), Koloa, HI, 2016, pp. 2903-2912. 